SISTEMA
ELETROANICO
DE REVISTAS
SER I UFPR

\title{
Evidenciação da responsabilidade social corporativa nos estudos sobre relato integrado: uma revisão estruturada da literatura
}

\section{Disclosure of corporate social responsibility on integrated report studies: a review of the literature}

Cíntia de Melo de Albuquerque RIBEIRO ${ }^{*}$, Júlio VIEIRA NETO ${ }^{1}$, José Paulo COSENZA ${ }^{1}$, Luis Perez ZOTES ${ }^{1}$.

${ }^{1}$ Universidade Federal Fluminense (UFF), Niterói, RJ, Brasil.

*E-mail de contato: cintiaalbuquerque@id.uff.br

Artigo recebido em 6 de agosto de 2019, versão final aceita em 4 de fevereiro de 2020, publicado em 23 de abril de 2020.

RESUMO: Atualmente, as empresas são cobradas cada vez mais a disseminar comunicados prestando contas de seu papel social e ambiental baseado no conceito de sustentabilidade. O Relato Integrado (RI) apresenta uma proposta de incorporação de dados financeiros e não financeiros relevantes sobre as atividades empresariais, integrando voluntariamente as preocupações sociais e ambientais às atividades operacionais e à tomada de decisões das empresas. Nesse sentido, este artigo tem como objetivo analisar o desenvolvimento da Responsabilidade Social Corporativa (RSC) na produção científica internacional sobre RI nas perspectivas da plataforma teórica, paradigmas de pesquisa, metodologias de investigação utilizadas e processo contábil. Para tanto, realizou-se uma revisão na base indexadora Scopus, pertinente à produção científica sobre o tema. Na análise dos dados consideram-se 52 artigos, publicados em revistas acadêmicas, no período de 2010 a junho de 2019, aplicando-se revisão estruturada da literatura para levantamento dos dados e utilizando a análise bibliométrica para tratamento e exame do seu conteúdo. Os resultados do estudo evidenciam a pouca ênfase dada à questão social e ambiental nas pesquisas acadêmicas sobre Relato Integrado, principalmente no que tange ao reconhecimento, classificação, mensuração e divulgação de eventos dessa natureza nesse tipo de relatório. O desafio está em desenvolver redes de pesquisa fortes e atuantes, com pesquisadores de diferentes áreas atuando de forma interdisciplinar na investigação de questões sociais, ambientais e de sustentabilidade em pesquisas de RI. Uma rede, apenas, foi identificada com duas publicações, revelando o pouco interesse no estudo de elementos que associem as práticas de RSC no processo de adoção e divulgação do RI pelas empresas. Também é importante que haja maior integração entre acadêmicos e profissionais, para que os resultados das pesquisas tenham resultados efetivos e práticos.

Palavras-chave: relato integrado; sustentabilidade; divulgação de informação financeira; divulgação de informação não financeira; bibliometria. 
ABSTRACT: Nowadays, companies' has been charged increasingly to disclosure their accountability of social environmental based on the concept of sustainability. The Integrated Report (IR) is a proposal to incorporate relevant financial and non-financial data on business activities, voluntarily integrating social and environmental concerns into corporate operational activities and decision-making. Therefore, this paper aims to analyze the development of Corporate Social Responsibility (CSR) in the international scientific production published in academic journals about Integrated Reporting (IR), from the perspectives of the theoretical platform, research paradigms and methodologies, and the utilized accounting process. For this purpose, a search was conducted in the Scopus indexing database, relevant to the scientific production on the topic and quotations. In the analysis of the data, 52 papers published in academic journals were considered within the period of 2010 to June, 2019, applying a structured review of the literature for data collection and using bibliometric study for the treatment and statistical analysis of its content. The results reveal the little emphasis given to social and environmental issues in academic research on IR, mainly regarding the identification, classification, measurement, and communication of such events in this type of report. The challenge is to develop strong and active research networks with researchers from different areas working in multidisciplinary contexts to investigate social, environmental, and sustainable issues in IR research. Only one network has been identified with two publications, revealing little interest in the study of elements that associate CSR practices and the process of adoption and disclosure of IR by the companies. Furthermore, it is of the utmost importance that academics and professionals interact so that the research findings can provide effective and practical benefits.

Keywords: integrated report; sustainability; disclosure of financial information; disclosure of non-financial information; bibliometrics.

\section{Introdução}

Tradicionalmente, as empresas sempre demonstraram maior preocupação com as questões associadas aos componentes econômicos, principalmente com o intuito de atender às expectativas e aos objetivos financeiros de seus shareholders. No entanto, com a crise financeira global que se seguiu ao ano de 2008, surgiram indagações sobre a utilidade dos modelos tradicionais de contabilidade e de relatórios existentes, uma vez que suas deficiências estavam implicadas na crise e, às vezes, sendo responsabilizadas por elas (de Villiers et al., 2017).

Em face aos questionamentos existentes e à insatisfação com os atuais modelos de relatórios contábeis, foi criado, em 2010, o IIRC (International Integrated Reporting Council) para discutir e definir diretrizes para uma nova metodologia de divulgação de informações empresariais que integrasse informações financeiras e não financeiras, o Relato Integrado (RI). Nesse relatório seriam fornecidas informações relevantes sobre a estratégia, a governança, o desempenho e as perspectivas da organização, de forma que o RI refletisse plenamente o contexto econômico, comercial, social e ambiental em que a empresa opera (Sierra-Garcia et al., 2015).

Portanto, as empresas passariam a perpassar os limites de natureza econômica, incluindo também aspectos interdisciplinares nos modelos gerenciais e produtivos dos seus negócios (Morais et al., 2017). Com isso, ainda que o lucro continue sendo indispensável ao resultado das empresas, em termos de sobrevivência, não se constitui mais na finalidade única do negócio, já que depende, cada vez mais, da eficiência na utilização dos recursos disponíveis 
e das motivações de todos os stakeholders que se relacionam com as atividades das companhias.

Em termos históricos, foi a partir do ano de 2013 que teve início uma crescente onda de publicação sobre o RI. Entretanto, Tweedie \& Martinov-Bennie (2015) argumentam que, apesar de sua rápida expansão, a literatura sobre o RI permanece subexplorada em comparação com a extensa análise de estruturas de relatórios não financeiros. Um dos pontos questionados pela literatura é relacionado ao afastamento do RI das questões de sustentabilidade (Flower, 2015; Thomson, 2015) e a sua abordagem limitada e unilateral para avaliar estas questões (Brown \& Dillard, 2014). Portanto, é necessário explorar como a pesquisa está evoluindo em relação a esse tema para que o mesmo não se torne mais um modismo administrativo/contábil aplicado ao mundo empresarial (Dumay et al., 2016).

Considerando esse panorama, surge a questão de pesquisa que motivou este estudo: "Como a teoria sobre RI tem se desenvolvido para atender à necessidade de divulgação de informações não financeiras e levar outras questões referentes à sustentabilidade a todos os públicos de interesse?" Isto se dá, em parte, porque a atual forma de divulgação dos relatórios de sustentabilidade das empresas não tem contribuído para esclarecer a efetividade das práticas de gestão sustentável e nem propiciado aos usuários informações sobre o processo de mutação patrimonial-financeira das entidades e sua consequente influência nos ambientes social e ecológico. Principalmente em termos de riscos e impactos negativos, fatores que podem contribuir com a destruição de valor organizacional.

Baseado nessa perspectiva, a presente pesquisa tem por objetivo analisar como a RSC é relacionada com estudos que contemplam o tema RI, tendo em vista que esse tipo de relatório representa a tentativa mais atual de propiciar uma comunicação integrada dos relatórios contábeis com as informações de natureza não financeira. Estimula-se uma discussão a respeito de um novo modelo de negócio que tem como base seis capitais: manufaturado, humano, intelectual, social, natural e financeiro (IIRC, 2013a). Com tal propósito, faz-se uma análise da evolução da produção científica sobre RI, identificando o desenvolvimento do tema e atualizando as lacunas e tendências de pesquisa por meio de uma análise exploratória e bibliométrica na base Scopus.

A realização da presente pesquisa justifica-se por três questões fundamentais: (i) examina como a literatura do RI aborda os fatos e riscos associados ao desenvolvimento sustentável, meio ambiente e sociedade; (ii) discute um tema que, apesar de sua rápida expansão na literatura internacional, ainda permanece subexplorado nas pesquisas brasileiras; e (iii) reflete sobre os caminhos necessários para o desenvolvimento da área, como alternativas de aproximar ou ressaltar as informações de RSC no RI, tornando a divulgação da sustentabilidade mais equilibrada.

Sob esse panorama, pretende-se contribuir para a discussão de um tema emergente e ainda não consolidado na literatura brasileira, agregando conhecimento tanto no campo teórico, através da sinalização dos paradigmas de pesquisa e perspectivas teóricas empregadas, como no campo prático, revelando bibliografia e revistas referentes ao tema e identificando tendências atuais e desafios futuros. Ao incluir essas perspectivas, torna-se factível delimitar fronteiras e lacunas nesta área de conhecimento. Estas perspectivas servirão de grande valia aos pesquisadores que pretendem aprofundar conhecimentos sobre este relatório de comunicação 
empresarial dirigido a evidenciar o processo de criação de valor nos negócios das empresas. Os pesquisadores e os preparadores das informações contábeis se beneficiarão com a discussão de formas de tornar as informações sobre sustentabilidade mais equilibrada no RI.

Para conduzir a presente discussão, além desta introdução, o artigo está organizado em cinco seções. A segunda seção contempla o fundamentação teórica, abordando os conceitos discutidos na responsabilidade social corporativa e as questões associadas ao papel do Relato Integrado. A terceira seção trata do método de pesquisa aplicado ao estudo, bem como sua delimitação. A quarta apresenta os dados da pesquisa e sua respectiva análise, sumarizando os principais resultados alcançados. Por fim, na última seção, são apresentadas as conclusões e considerações finais sobre o assunto, seguidas da bibliografia utilizada como referência no trabalho.

\section{Fundamentação teórica}

A responsabilidade social das empresas vem sendo um tema muito discutido e exigido em todas as esferas da sociedade. Assim, nos últimos anos, vêm se ampliando as pressões e exigências em torno das empresas para que divulguem informações sobre suas atuações pautadas na perspectiva do desenvolvimento sustentável, evidenciando as ações dirigidas a minimizar os impactos de degradação ao meio ambiente e reduzir os desequilíbrios sociais próprios das práticas de desenvolvimento econômico promovidas pelo modelo econômico capitalista vigente.

Historicamente, as preocupações éticas, sociais e ambientais passaram a ser discutidas, mais amplamente, no contexto norte-americano nos anos 1950, época em que os religiosos dos Estados Unidos observavam a atuação das empresas e desconfiavam dos argumentos dos empresários quanto à benevolência de suas ações, fato que os levou a começar a preocupar-se com a responsabilidade social das empresas.

Os anos 1970 corresponderam a um maior interesse por parte das empresas por esse tema, inclusive no Brasil, onde a responsabilidade social foi abordada inicialmente por entidades católicas (Tachizawa, 2014). A partir de 1990, houve um interesse maior da sociedade sobre o assunto, e a responsabilidade social passou a enfatizar o impacto das atividades da empresa com os stakeholders (Tinoco, 2001). Com esse intuito, começou-se a formular indicadores de responsabilidade social e sustentabilidade, buscando introduzir ferramentas de gestão sustentável e cobrar das empresas uma mobilização em prol da sustentabilidade e do desenvolvimento sustentável.

Essa mobilização precisa ter em mente, no entanto, que o contexto mundial mudou, principalmente em relação aos aspectos associados ao crescimento social e à degradação ambiental.

Da mesma forma, o mercado de capitais mudou. De acordo com a Ocean Tomo (2019), no último quarto de século, os ativos intangíveis superaram os ativos tangíveis, passando a ser o principal componente do valor de mercado das empresas. Há 44 anos, os ativos tangíveis (bens corpóreos) representavam, em média, cerca de $80 \%$ do valor registrado nos Balanços Patrimoniais divulgados pelas empresas de capital aberto, e $20 \%$ apenas referentes aos ativos intangíveis (bens incorpóreos). Nos dias de hoje, essa relação se inverteu. No campo empresarial, os reguladores globais também 
mudaram. Atualmente, os organismos de regulação do mercado financeiro nacional e internacional, em face do surgimento de inúmeros casos de corrupção empresarial, vêm demandando das empresas mecanismos de disclosure, accountability e compliance, de modo a certificar a confiabilidade das demonstrações contábeis por elas divulgadas e evidenciar a conduta das mesmas diante do meio ambiente, face à crescente preocupação da sociedade com a preservação da vida, dos recursos naturais e do ecossistema do planeta. Por conta disso, assiste-se, nas últimas décadas, a uma ampliação do movimento por parte das instâncias reguladoras, particularmente aquelas que lidam com questões referentes ao mercado de capitais, dirigido a exigir uma maior transparência dos negócios, de modo a evidenciar, de forma clara e concisa, informações do gerenciamento dos recursos econômico-financeiros e das ações socioambientais, bem como a forma que a companhia adota para criar valor no curto, médio e longo prazo.

Para citar apenas alguns exemplos, a Organização das Nações Unidas (ONU) lançou o guia Best practice guidance for policymakers and stock exchanges on sustainability reporting initiatives, onde tenta orientar bolsas de valores e reguladores sobre a publicação de "Relatório de Sustentabilidade" (United Nations, 2014). A Sustainable Stock Exchanges Initiative - SSE (http://www.sseinitiative.org/) publica o Report on progress a cada dois anos, em que divulga as iniciativas de sustentabilidade em Bolsas de Valores ao redor do mundo (SSE, 2018). Também a Comissão Europeia aprovou diretrizes que regulam um modelo denominado "Relate ou Explique", que diz respeito à divulgação de informações não financeiras e de diversidade por grandes empresas e grupos econômicos cujo número de trabalhadores ultrapasse a 500 empregados. O objetivo dessa regulação é aumentar a accountability e o desempenho da empresa, bem como a eficiência do mercado de capitais por meio do modelo "relatar ou explicar", em que as empresas podem escolher entre o relatório real ou, alternativamente, divulgar as razões para não fazê-lo (European Comission, 2013).

Diante dessa tendência internacional, os reguladores locais também mudaram. A CVM (Comissão de Valores Mobiliários), o BACEN (Banco Central do Brasil) e a B3 (Brasil, Bolsa, Balcão) publicaram regulamentações nessa mesma linha, ou seja, estimulando as companhias listadas a divulgarem informações relacionadas às dimensões sociais, ambientais e de governança corporativa no modelo "Relate ou Explique" para o Relatório de Sustentabilidade ou o Relato Integrado. O objetivo é ampliar a transparência para os investidores (Resolução BACEN n. ${ }^{\circ} 4.327$ e Instrução CVM n. ${ }^{\circ}$ $552 / 2014$ ), bem como as recomendações de boas práticas de governança e códigos de conduta e ética profissionais.

Os investidores dos mercados de capitais globais começaram a alterar suas opções de investimento, incluindo critérios ambientais, sociais e de governança na lógica dos seus investimentos e buscando empresas socialmente responsáveis, sustentáveis e rentáveis para investir seus recursos.

Enfim, o mundo moderno é representado por uma sociedade em constante ebulição, em que tudo está mudando e muito rapidamente. Para comprovar-se tal fato, basta uma rápida mirada no site www.worldometers.info/pt/ para verificação das estatísticas mundiais em tempo real.

Obviamente que num contexto em que tudo se mostrou em sistemática mutação, os relatórios contábeis também não poderiam deixar de mudar. 
A necessidade de maior disclosure empresarial vem forçando, ao longo do tempo, a alteração da maneira como as empresas contam sua história. Um olhar na evolução cronológica dos principais relatórios financeiros e não financeiros utilizados mostra que, no período de 1960 a 1980, as demonstrações contábeis eram hegemônicas. Entre 1980 e 2000, começaram a ser elaborados relatórios não financeiros, como o de sustentabilidade, de governança e de administração, ainda que de forma incipiente (cf. Fonseca, 2015). A partir dos anos 2000, estes novos relatórios tiveram um melhor desenvolvimento, tornando-se mais robustos. Entretanto, ainda faltava integrar as informações de caráter financeiro com as não financeiras, o que é proposto pelo Relato Integrado.

A publicação do RI cresce cada vez mais, mostrando-se claro que a integração dos tradicionais relatórios financeiros é uma nova tendência, e os aspectos "não financeiros", contabilmente reconhecidos como intangíveis, passam agora a ser o novo valor financeiro dos empreendimentos (KPMG, 2017 , p. 7, 21). Isso ocorre, em parte, porque as demonstrações contábeis tradicionais têm sido muito criticadas, não só pelo volume de informação produzido, mas também por não mais satisfazer às necessidades de informação dos stakeholders na sua avaliação do desempenho financeiro passado, presente e futuro das empresas (Eccles \& Serafeim, 2015).

Neste sentido, Jensen \& Berg (2012) ressaltam que, para superar os obstáculos dos relatórios tradicionais de sustentabilidade, é necessária uma visão holística dos negócios, incluindo metas futuras entre desempenho financeiro e responsabilidade social e ambiental corporativa. Soyka (2013) acrescenta que retirar o foco do curto prazo é importante para melhorar o desempenho da organização e sua sustentabilidade social, ambiental e de governança.

Portanto, o RI mostra-se como uma forma de integrar, em um relatório conciso e coerente, informações financeiras e não financeiras relevantes sobre as atividades criadoras de valor das empresas (de Villiers et al., 2014; 2015; 2016; Dumay et al., 2016; Rinaldi et al., 2018). Com isso, o RI torna-se uma nova ferramenta para representação concisa sobre como a estratégia, a governança, o desempenho e as perspectivas de uma organização, no contexto de seu ambiente externo, levam à geração de valor ao longo do tempo (IIRC, 2013b, p. 7).

Por conseguinte, o RI oferece uma nova estrutura de relatório focada na narrativa de criação de valor futuro das empresas (de Villiers et al., 2016). Com o fim de buscar uma melhor qualidade e credibilidade do tipo de informação contida no RI, o IIRC enfatizou o papel da governança corporativa na preparação de um relatório de alta qualidade, alinhado ao International Framework $<I R>$, cujo principal objetivo é explicar aos fornecedores de capital financeiro como as organizações criam e sustentam valor ao longo do tempo (IIRC, 2013a). Especificamente, o objetivo desse tipo de relato é desenvolver uma abordagem unificada de relatórios integrados (Kuzina, 2014) e fazer com que tanto os gestores quanto os provedores de capital financeiro considerem as consequências em longo prazo de um conjunto mais amplo de capitais (de Villiers et al., 2016).

Assim, o RI, como o nome diz, integra informações quantitativas, advindas da contabilidade, com informações qualitativas, oriundas de diversas áreas da organização, para relatar seis capitais (financeiro, manufatureiro, natural, intelectual, humano, social e de relacionamento), considerando 
seu modelo de negócios e governança corporativa. Conforme Adams \& Simnett (2011), o RI é um novo paradigma de relato, de caráter holístico, estratégico e responsivo, que pode representar a próxima evolução da contabilidade, ao conter material relevante em vários prazos.

No entanto, é preciso atentar mais profundamente ao seu conteúdo, já que o RI vem se afastando de questões de sustentabilidade (Flower, 2015; Thomson, 2015) e fornecendo uma abordagem limitada e unilateral para avaliar estas questões, da forma como foi concebido pelo IIRC em 2013 (Brown \& Dillard, 2014). Apesar disso, Soyka (2013) esclarece que a adoção do $<$ IR $>$ pelas organizações pode provocar mudanças drásticas nas formas pelas quais elas pensam e preparam as divulgações de sustentabilidade e outros dados.

Corroborando essa ideia, Tweedie \& Martinov-Bennie (2015) defendem que o RI pode contribuir para a sustentabilidade de três formas: (1) envolvendo organizações que, de outra forma, não divulgariam nenhuma informação social e ambiental; (2) para as partes interessadas levantarem questões de sustentabilidade em nível gerencial que, de outra forma, seriam excluídas do discurso organizacional; e (3) melhorando os resultados de sustentabilidade, se fizer parte de uma mudança mais ampla na elaboração de relatórios corporativos e de investimento em uma perspectiva de longo prazo.

Existem diversas pesquisas que comprovam alguns benefícios elencados na literatura para adoção do RI, como redução no custo do capital (García-Sánchez \& Nogueira-Gómez, 2017; Zhou et al., 2017), melhoria no preço da ação (Rambe \& Mangara, 2016; Giorgino et al., 2017), aumento do lucro e do valor contábil (Baboukardos \& Rimmel, 2016), ou ainda, na divulgação de RI com quali- dade, como melhoria na avalição da empresa e no processamento de informações (Lee \& Yeo, 2016) e no valor da empresa, na liquidez, no fluxo de caixa futuro esperado e na eficiência dos investimentos (Barth et al., 2017).

\section{Método}

Trata-se de uma pesquisa descritiva que retrata e avalia as características das publicações sobre RI que abordem questões sobre o meio ambiente, a sociedade, a responsabilidade social e a sustentabilidade. No que se refere aos procedimentos técnicos empregados, além da revisão estruturada da literatura para levantamento dos dados, utilizou-se a técnica da bibliometria para o tratamento e análise estatísticos. A aplicação dessa metodologia permitiu mensurar a frequência dos dados e de redes bibliométricas presentes nas publicações, visando efetuar uma análise de coautoria, cocitação, coocorrência de palavras-chave e acoplamento bibliográfico.

A revisão estruturada da literatura usa um processo que, por meio de um conjunto de regras, oferece menos preconceito e mais transparência na execução da pesquisa e medidas e técnicas de validação e confiabilidade (Massaro et al., 2016). Realizou-se, portanto, uma revisão estruturada da literatura do que vem sendo publicado numa das principais bases de dados internacionais.

Quanto à bibliometria, essa abordagem permitiu realizar o estudo quantitativo da bibliografia existente, analisando, conforme Bonjardim et al. (2018), a produtividade dos autores (Lei de Lotka), a produtividade dos periódicos (Lei de Bradford) e o modelo de distribuição e frequência de palavras num texto (Lei de Zipf). 
Para a análise de redes bibliométricas, utilizou-se o software VOSviewer. Este programa permite construir e visualizar mapas de redes bibliométricas e, ao contrário de outros aplicativos, é especialmente útil para a representação gráfica de mapas de redes bibliométricas e de fácil interpretação (Van Eck \& Waltman, 2010).

A fonte de dados escolhida para realização da pesquisa foi a base Scopus. Assinale-se que esta é a maior base de dados de citações e resumo de literatura revisada por pares, além de oferecer ferramentas inteligentes para rastrear, analisar e visualizar a pesquisa, fornecendo uma visão abrangente da produção mundial de pesquisa em todas as áreas do conhecimento (Elsevier, 2019).

O levantamento dos dados foi realizado procedendo-se à busca de artigos nos campos de título, resumo e palavras-chave, limitada pelo ano de pesquisa. Estabeleceu-se como período inicial o ano de criação do IIRC, 2010, seguindo até a data de realização da pesquisa, 22 de junho de 2019. Na busca realizada, classificou-se por tipo de fonte (artigos publicados em journals) e tipo de documento (artigos revisados por pares). Primeiramente, foi realizada uma busca com a expressão "integrated report” or “integrated reporting”. Nesse levantamento, foram encontrados 353 documentos. Entretanto, quando a pesquisa se tornou mais específica e foram inseridos termos ligados à responsabilidade socioambiental, este número viu-se reduzido em quase $40 \%$, passando a contar com 211 documentos.

Esses documentos foram filtrados pela leitura de seus resumos, a fim de identificar sua aderência ao estudo. $\mathrm{O}$ objetivo foi selecionar os artigos que tivessem relação com o RI no escopo do IIRC e que, ao mesmo tempo, abordassem questões de responsabilidade social das empresas, ou seja, abordassem questões sociais, de meio ambiente e de sustentabilidade. Após este filtro, a amostra ficou com 52 artigos.

Com esta amostra final, procedeu-se à leitura da introdução, metodologia e considerações finais para categorização dos artigos e identificação das lacunas existentes. As categorias se referem às informações gerais e metodológicas e foram adaptadas de Reis \& Tarifa (2014), Mohamed \& Ahmed (2014), Slewinski (2015) e Dumay et al. (2016). São apresentadas de forma detalhada na tabela 1 com seus respectivos resultados.

As categorias temáticas foram elaboradas a partir da ótica que orienta o processo contábil tradicional: reconhecimento, classificação, mensuração e divulgação, aplicando-se, neste caso, aos fatos ambientais e sociais presentes nos artigos analisados. No grupo de informações gerais foi utilizado o termo "não se aplica" para jurisdição e país ou região, quando a pesquisa não tinha base empírica na jurisdição.

Para a classificação, segundo o processo contábil, foi adotado o seguinte critério: i) reconhecimento: quando abordava a questão de identificação, de quais informações deveriam ser divulgadas, ou seja, reconhecidas no RI; ii) classificação: quando tratava de como classificar, onde agrupar no RI; iii) mensuração: quando abordava a questão de como mensurar ou de indicadores; iv) divulgação: quando tratava da evidenciação da informação, de como tem sido feita a divulgação das informações, ou ainda, as práticas de divulgação no RI, em todos os casos, sempre relacionada à questão ambiental ou social; e v) outras: quando não se tratava especificamente de nenhuma das quatro atividades anteriores referentes ao processo contábil. 
O processo de categorização foi realizado e harmonizado de forma autônoma por dois dos autores, com base na experiência dos mesmos, sendo revisado posteriormente pelos outros dois de forma independente, com o objetivo de garantir a confiabilidade e validade dos dados.

\section{Resultados e discussão}

Os resultados da bibliometria e da análise exploratória são apresentados e discutidos a seguir, mostrando a evolução da produção no campo em estudo, a categorização dos resultados e as lacunas identificadas, bem como sugestões para pesquisas futuras.

\subsection{Evolução da produção no campo de estudo}

O quantitativo de publicação científica sobre o tema RI é apresentado na Figura 1, sendo que dos 353 documentos que abordam o tema, menos de $15 \%$ tratavam da relação do RI com a RSC e com as questões ambientais.
Em 2015, houve um pico de 16 publicações abrangendo as questões socioambientais. Esse ano foi de intensa discussão entre críticos e defensores sobre a relação do RI com a sustentabilidade (ver Adams, 2015; Flower, 2015; Tweedie \& Martinov, 2015). Os anos seguintes tiveram um número bem reduzido de discussões abordando a questão socioambiental dentro do RI, não acompanhando a expansão de publicações sobre esse tema, principalmente nos anos de 2018 e 2019.

\subsection{Produtividade dos autores e dos periódicos}

Com relação aos pesquisadores mais produtivos, identificou-se Gaia Melloni e Warren Maroun com três publicações cada um. Melloni representa dois países com elevada produtividade sobre RI, sociedade e meio ambiente, Reino Unido e Itália, enquanto Maroun representa a instituição com maior número de pesquisas publicadas, a Universidade de Witwatersrand, em Joanesburgo, África do Sul. Ressalte-se que esse país, juntamente com a Itália, está em segundo lugar no ranking dos países

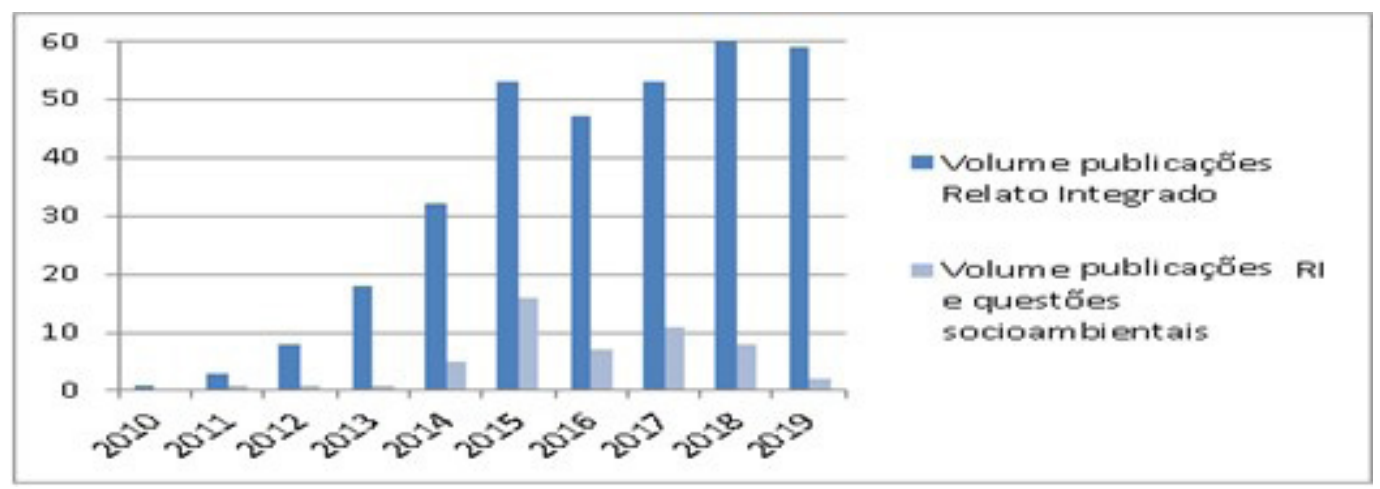

FIGURA 1 - Evolução da produção científica sobre relato integrado. 
com maior geração de publicações sobre o tema em pauta, enquanto o Reino Unido está em primeiro. Assim, estes três países podem ser considerados núcleos de desenvolvimento de pesquisa sobre o tema.

Apesar de Melloni \& Maroun serem os mais produtivos, não são os autores mais citados. Esse recorde pertence a John Flower (129 citações) e Carol Alison Adams (110 citações). Ressalte-se que Flower, com apenas um documento, consegue destacar-se com um número de citações mais expressivo. Adams, por sua vez, é a segunda autora mais citada, porém tem duas publicações, sendo a mais referenciada aquela que analisa o artigo de Flower, trabalho este que discute a evolução do IIRC e argumenta que o RI abandou os princípios que fundamentam a questão da sustentabilidade.

Os seis pesquisadores mais produtivos (com mais de uma publicação) somam 16 publicações, as demais publicações estão distribuídas entre os outros 96 pesquisadores. Este resultado vai de encontro com a Lei de Lotka, já que este pequeno grupo não é responsável pela maior parte da produção científica nesta área. Entretanto, isto pode dar-se pelo fato de não se estar pesquisando a área do RI como um todo, e sim uma parte específica relacionada às publicações de RI que abordam as questões sociais e ambientais.

Na Tabela 1, relaciona-se o conjunto de artigos referência, assumindo sua relevância por serem mais citados.

Os artigos mais relevantes estão publicados nos três periódicos que mais se dedicam ao tema, dentre os dez com uma ou mais publicação, conforme mostrado na Tabela 2. Interpretando este resultado com base na Lei de Bradford, pode-se afirmar que estes periódicos seriam os de maior qualidade e relevância sobre o tema. A revista Accounting, Auditing and Accountability Journal se destaca com cinco publicações. Apesar disso, a revista que recebeu mais citações foi a Critical Perspectives on Accounting (281). Esta classificação pode resultar do fato de que os trabalhos mais citados, os de Flower e Adams, como colocado anteriormente, haver sido publicados nessa conceituada revista, o que pode ter alavancado a quantidade de citações da mesma.

TABELA 1 - Autores com artigos mais relevantes nos trabalhos estudados.

\begin{tabular}{lcll}
\hline \multicolumn{1}{c}{ ARTIGO } & ANO & \multicolumn{1}{c}{ TÍTULO } & \multicolumn{1}{c}{ PERIÓDICO } \\
\hline Flower & 2015 & $\begin{array}{l}\text { The international integrated reporting council: A story } \\
\text { of failure }\end{array}$ & $\begin{array}{l}\text { Critical Perspectives on } \\
\text { Accounting }\end{array}$ \\
\hline Jensen \& Berg & 2012 & $\begin{array}{l}\text { Determinants of Traditional Sustainability Reporting } \\
\text { Versus Integrated Reporting. An Institutionalist } \\
\text { Approach }\end{array}$ & $\begin{array}{l}\text { Business Strategy and the } \\
\text { Environment }\end{array}$ \\
\hline $\begin{array}{l}\text { Adams } \\
\text { Brown \& }\end{array}$ & 2015 & $\begin{array}{l}\text { The international integrated reporting council: A call } \\
\text { to action }\end{array}$ & $\begin{array}{l}\text { Critical Perspectives on } \\
\text { Accounting }\end{array}$ \\
\hline $\begin{array}{l}\text { Sillard } \\
\text { Higgins }\end{array}$ & 2014 & $\begin{array}{l}\text { Integrated reporting: On the need for broadening out } \\
\text { and opening up }\end{array}$ & $\begin{array}{l}\text { Accounting, Auditing \& } \\
\text { Accountability Journal }\end{array}$ \\
\hline
\end{tabular}




\begin{tabular}{lcc}
\hline \multicolumn{1}{c}{ REVISTA } & PUBLICAÇÕES & CITAÇÕES \\
\hline Accounting Auditing and Accountability Journal & 5 & 269 \\
Business Strategy and the Environment & 4 & 170 \\
Critical Perspective on Accounting & 3 & 281 \\
\hline
\end{tabular}

As redes de coautoria permitem a identificação de redes de pesquisadores, instituições de pesquisa ou países ligados com base no número de publicações que eles criaram em parceria (Van Eck \& Waltman, 2014). Foi possível observar que as publicações sobre RI são bastante fragmentadas. Existe apenas uma rede de pesquisa atuante no desenvolvimento de pesquisas de RI e questões sociais e ambientais, formado por Gaia Melloni, Alessandro Lai \& Riccardo Stacchezzini, com uma pequena produção de dois artigos publicados pela rede.

Para identificar as referências que são citadas juntas, foi utilizada a análise de cocitações. Esta identifica duas referências citadas por uma terceira. Quanto maior o número de publicações pelas quais as duas referências são cocitadas, mais forte é a relação de cocitação (Van Eck \& Waltman, 2014). $\mathrm{O}$ requisito foi de que a referência citada tivesse um mínimo de cinco citações, e o resultado gerado está apresentado na Figura 2, em que cada uma das cores representa um cluster. As pesquisas dentro de cada cluster são as que mantêm maior parentesco.

As pesquisas de Flower e Adams representam crítica e defesa do RI, respectivamente. Brown \& Dillard (2014) investigam as práticas de divulgação do RI, enquanto Stubbs \& Higgins (2014) examinam as práticas de elaboração. As pesquisas de Suchman (1995), Jensen \& Berg (2012) e Milne \& Gray (2013) têm relação com relatórios de sustentabilidade.
Para compreender-se melhor o motivo destes artigos serem citados juntos, é importante conhecer sua essência e seu arcabouço teórico de origem. Nesse sentido, o acoplamento bibliográfico permite identificar artigos semelhantes, que utilizam referências em comum. Assim, quanto maior o número de referências que duas publicações têm em comum, mais intensa é a relação de acoplamento bibliográfico entre elas (Van Eck \& Waltman, 2014).

A Figura 3 demonstra a força da relação existente entre os documentos, sendo que quanto mais próximo o nó de um documento do outro, mais forte é sua relação. Os documentos são agrupados em três grupos de relacionamento.

O cluster azul é formado por Brown \& Dillard (2014) e Van Bommel (2014). Enquanto o primeiro autor buscou investigar a multiplicidade de visões sobre o RI, esses últimos autores avaliaram criticamente o RI. Para Brown \& Dillard (2014), o $\mathrm{RI}$, conforme concebido pelo IIRC, fornece uma abordagem muito limitada e unilateral para avaliar e relatar as questões de sustentabilidade. Van Bommel (2014) complementa esse pensamento, ao afirmar que há um risco de que os relatórios integrados sejam capturados por investidores e contadores, levando a arranjos privados locais, em vez de compromissos legítimos duráveis. Neste sentido, ambos os pesquisadores têm uma visão crítica à proposta e forma de adoção do RI. 
flower, j., the international

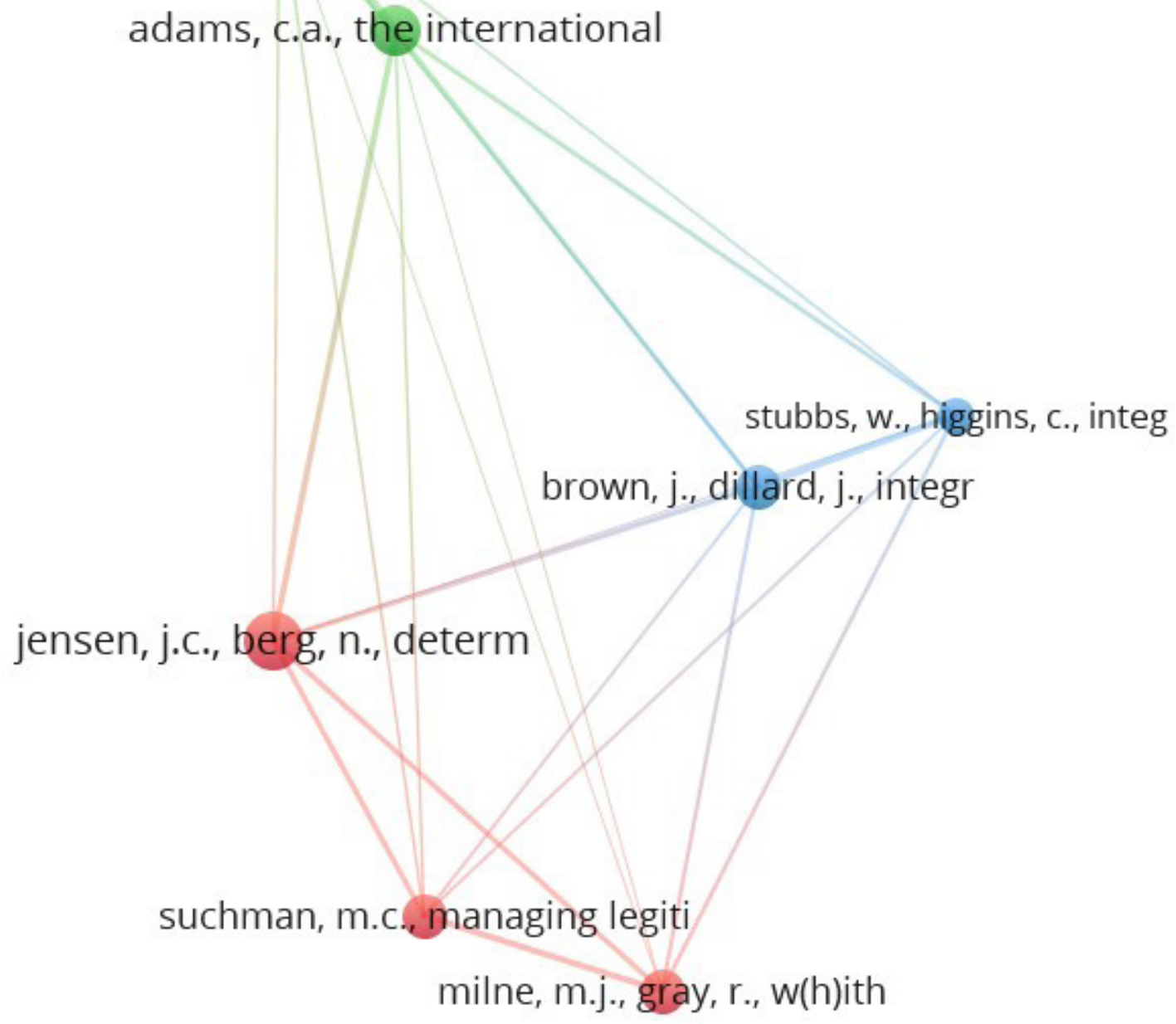

FIGURA 2 - Rede de cocitação de autores nos trabalhos estudados. 


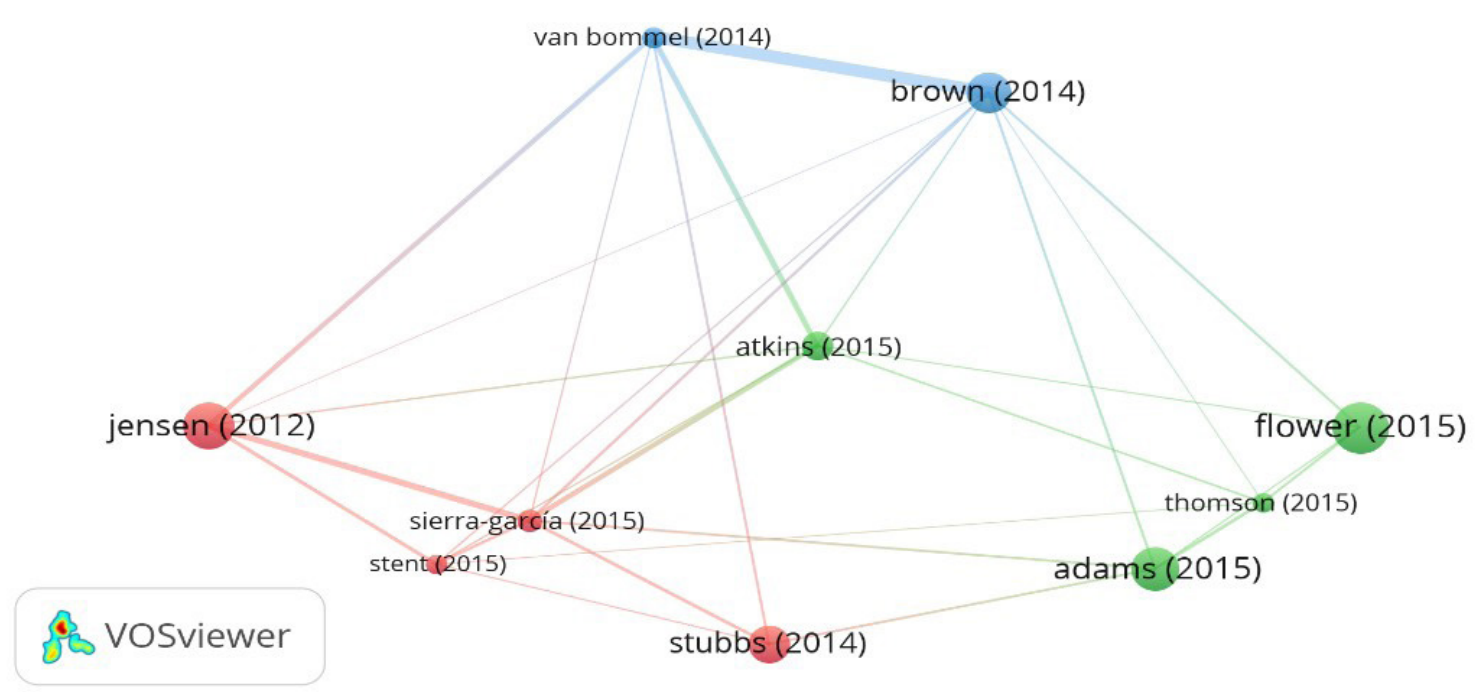

FIGURA 3 - Rede de colaboração em coautoria nos trabalhos estudados.

O cluster verde é composto por pesquisadores críticos ao RI, pelo seu afastamento da contabilidade de sustentabilidade (Flower, 2015; Thomson, 2015) e por defensores (Adams, 2015; Thomson, 2015). Especificamente, o artigo de Adams é uma análise do artigo de Flower, em que a autora contra-argumenta as colocações deste autor.

O cluster vermelho reúne documentos de anos diversos, cujas pesquisas estavam relacionadas às empresas, seja para identificar fatores que impulsionam a adoção do relatório (Jensen \& Berg, 2012; Sierra-Garcia et al., 2015) ou para investigar os processos internos dos adotantes (Stubbs \& Higgins, 2014; Stent \& Dowler, 2015).

A frequência com a qual uma palavra ocorre também pode contribuir para a análise de como a pesquisa se comporta. Para isso foi gerada uma nuvem de palavras, conforme se apresenta na Figura 4.
É possível observar a forte relação entre o RI e a sustentabilidade e a RSC, provavelmente decorrente do filtro da pesquisa que se utilizou destas palavras-chave para gerar a amostra de documentos para o estudo. De qualquer forma, a literatura mostra que o RI nasceu no berço da sustentabilidade. No entanto, apesar de ser útil a qualquer tipo de usuário dessa informação, o principal beneficiado por este tipo de relatório que permite a análise da criação de valor pela organização é o acionista.

Entretanto, o termo que mais aparece na nuvem de palavras é stakeholder, e não investidor. Talvez pela existência de um número grande de pesquisas que investigam o valor do RI para os demais usuários dessa informação e pelo uso da teoria dos stakeholders. Outras duas teorias fortemente influentes nas pesquisas são a da legitimidade e a institucional. 


\section{disclosure}

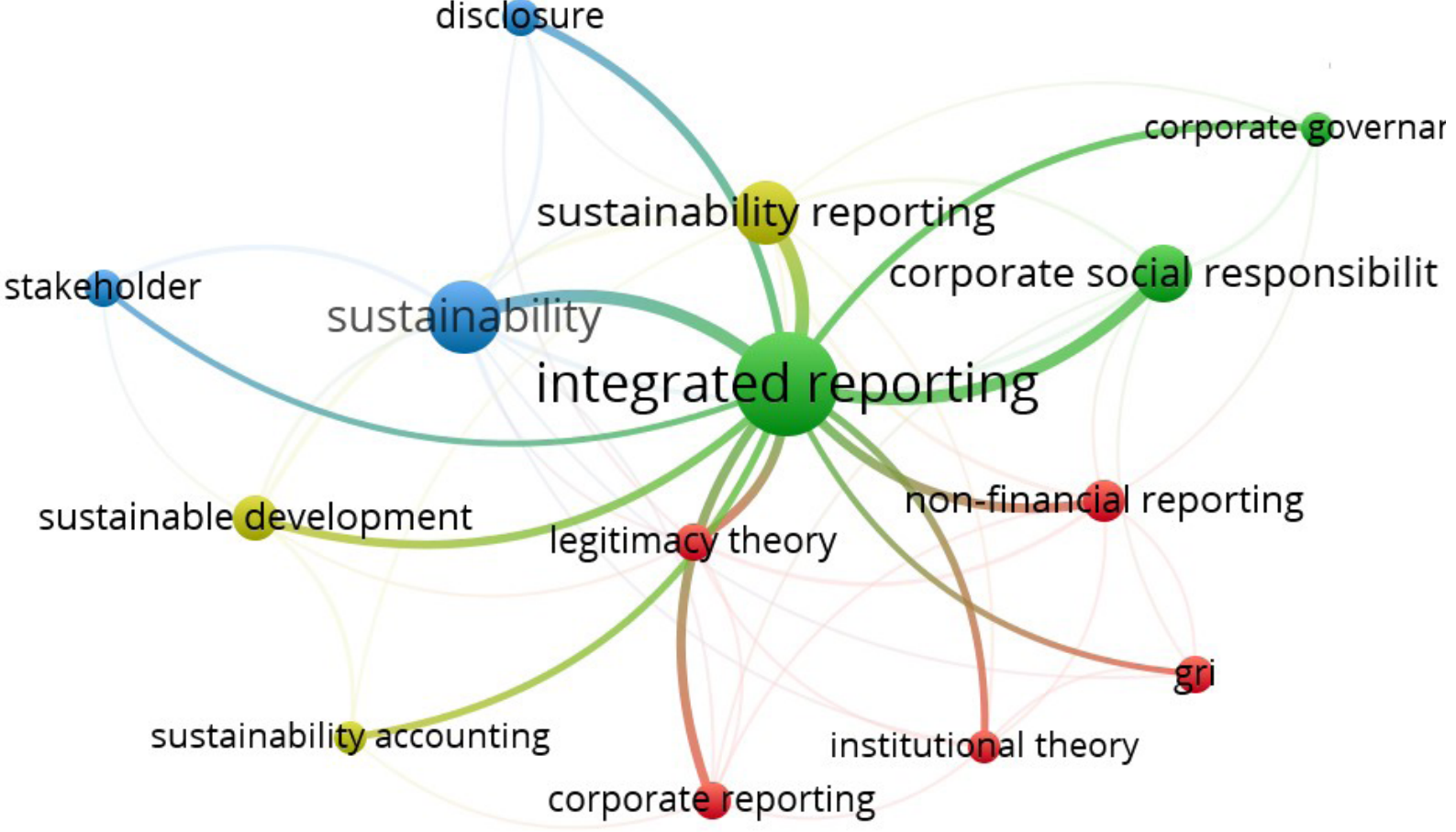

FIGURA 4 - Nuvem de palavras mais citadas.

\subsection{Apresentação e análise das categorias}

Os resultados da categorização dos dados estão apresentados na Tabela 3, em termos absolutos (Abs.), quantidade de artigo em cada categoria, e em termos relativos (Relat.), percentual de artigos classificados em cada categoria.

\subsubsection{Informações gerais}

As categorias que compõem o grupo de informações gerais foram adaptadas de Dumay et al.
(2016), com objetivo de identificar a jurisdição da pesquisa, o foco organizacional, o país ou a região que está sendo estudada e o perfil do pesquisador.

No que tange à jurisdição, a maior parte das pesquisas investigou a Europa (oito pesquisas) e a África do Sul (sete pesquisas). A maior quantidade de trabalhos investigando estas regiões pode estar relacionada às origens do RI, uma vez que foi na Europa que a Global Reporting Initiative (GRI) e o Projeto Contábil para Sustentabilidade do Prince of Wales (A4S) formaram o IIRC em 2010. Além disso, esta região foi berço da iniciativa Prince of Wales "Contabilidade para a sustentabilidade", que 
TABELA 3 - Caracterização metodológica dos artigos pesquisados.

\begin{tabular}{|c|c|c|c|c|c|}
\hline \multicolumn{3}{|l|}{ INFORMAÇÕES GERAIS } & \multicolumn{3}{|c|}{ INFORMAÇÕES METODOLÓGICAS } \\
\hline 1. Jurisdição & Abs. & Relat. & 1. Abordagem Paradigmática & Abs. & Relat. \\
\hline Sem base empírica & 14 & $27 \%$ & Positiva & 12 & $23 \%$ \\
\hline Organização específica & 5 & $10 \%$ & Crítica & 21 & $40 \%$ \\
\hline Regiões ou nações diversas & 15 & $29 \%$ & Interpretativa & 4 & $8 \%$ \\
\hline 2. Foco organizacional & Abs. & Relat. & 2. Estratégia de pesquisa & Abs. & Relat. \\
\hline Empresa listada & 8 & $15 \%$ & Bibliográfica & 5 & $10 \%$ \\
\hline Privada - PME & 1 & $2 \%$ & Documental & 23 & $44 \%$ \\
\hline Privada - Outras & 8 & $15 \%$ & Experimental & 11 & $21 \%$ \\
\hline Outros & 12 & $23 \%$ & & & \\
\hline Não se aplica & 14 & $27 \%$ & & & \\
\hline Total & 52 & $100 \%$ & Total & 52 & $100 \%$ \\
\hline 3. País ou Região & Abs. & Relat. & 3. Técnica de pesquisa & Abs. & Relat. \\
\hline EUA e Canadá & 1 & $2 \%$ & Análise de conteúdo & 5 & $10 \%$ \\
\hline Austrália e Ásia & 4 & $8 \%$ & Análise documental & 18 & $35 \%$ \\
\hline Europa & 12 & $23 \%$ & Entrevista/Questionário & 2 & $4 \%$ \\
\hline África do Sul & 7 & $13 \%$ & Observação & 0 & $0 \%$ \\
\hline Total & 52 & $100 \%$ & Total & 52 & $100 \%$ \\
\hline 4. Escrito por & Abs. & Relat. & 5. Tipo de pesquisa & Abs. & Relat. \\
\hline Acadêmicos & 42 & $81 \%$ & Exploratório & 19 & $37 \%$ \\
\hline Profissionais & 3 & $6 \%$ & Descritivo & 21 & $40 \%$ \\
\hline \multirow[t]{2}{*}{ Acadêmicos e profissionais } & 7 & $13 \%$ & Explicativo & 0 & $0 \%$ \\
\hline & & & Empírico-analítico & 12 & $23 \%$ \\
\hline Total & 52 & $100 \%$ & Total & 52 & $100 \%$ \\
\hline 6. Área disciplinar & Abs. & Relat. & 7. Perspectivas teóricas & Abs. & Relat. \\
\hline Ciências Sociais Aplicadas & 37 & $71 \%$ & Stakeholders & 9 & $17 \%$ \\
\hline
\end{tabular}




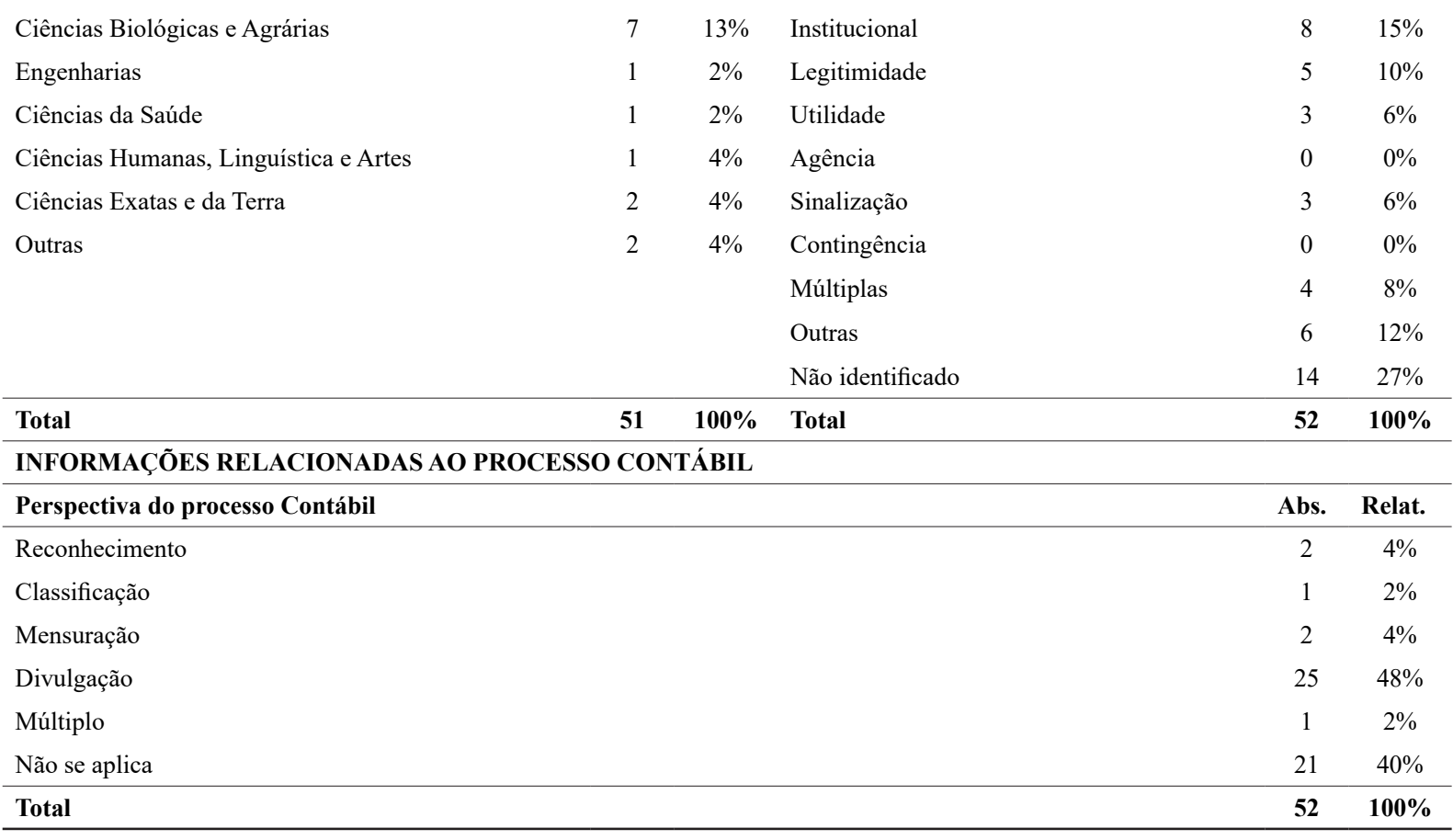

apresentou um documento denominado "Connected reporting framework" em 2007 e "Connected reporting como orientar" em 2009. Em 2017, a elaboração de relatórios integrados passou a ser obrigatória para as grandes empresas, de acordo com a Diretiva 2014/95/EU.

Já a África do Sul foi o primeiro país onde a divulgação de relatórios integrados se tornou obrigatória para as empresas listadas na JSE em 2010 com o desenvolvimento do Relatório do Rei sobre Governança para a África do Sul - King III. A jornada de relatórios integrados nesta região começou de forma pioneira em 1994, com a criação do Código de Governança Corporativa do Reino da África do Sul, comumente conhecidos como "Rei I". As pesquisas são, principalmente, sobre a aderência do conteúdo destes relatórios ao framework do RI, tanto na África do Sul (cf. Buys \& Van Niekerk, 2014; Ahmed Haji \& Anifowose, 2017; Van Zijl et al., 2017), quanto na Europa (cf. Turturea, 2015; Romero et al., 2018; Woźniak \& Pactwa, 2019).

Muitas publicações, aproximadamente $27 \%$, não dispõem de base empírica e têm por objetivo discutir a estrutura do RI (cf. Soyka, 2013; Brown \& Dillard, 2014; Siew, 2015) ou seu processo de construção e evolução (cf. Mio \& Fasan, 2014; Flower, 2015; Reuter \& Messner, 2015; Alexander \& Blum, 2016).

Em relação ao foco organizacional, $50 \%$ das publicações estão classificados na categoria "outros". Ou seja, a unidade de análise não se enquadra em nenhuma das categorias informadas, ou não 
se aplica, por estarem, geralmente, relacionados a estudos sem base empírica. As outras categorias significativas concentram pesquisas com foco em empresas listadas, em grandes empresas privadas não listadas e nas empresas participantes do programa piloto do IIRC. Metade das pesquisas realizadas com empresas listadas é referente às empresas da África do Sul, dada a condição obrigatória para que essas empresas publiquem relatórios integrados desde 2010.

$\mathrm{O}$ interesse em empresas pioneiras na adoção do RI, ou seja, participantes do programa piloto, e nas listadas na Bolsa de Valores de Johanesburgo, dá-se pela possibilidade de trabalhar-se com os dados históricos, já que são empresas que têm maior número de relatórios integrados publicados, dado sua adoção há mais tempo. As pesquisas relacionadas a outras empresas privadas são, em 50\% dos casos, de empresas europeias, principalmente após o RI ter se tornado obrigatório por determinação da União Europeia em 2017.

Na categoria país ou região, a maior concentração de estudos se dá em artigos relacionados às pesquisas sem base empírica, como na categoria anterior. Entretanto, os resultados mais significativos colocam a Europa e a África do Sul em evidência, o que corrobora as informações das categorias anteriores. Ressalta-se que $70 \%$ das pesquisas referentes à Europa foram publicadas após 2017. Pesquisas que envolvem diversos países também se destacam pelo uso de amostras que têm como base de dados países de todo o mundo.

Mais de $80 \%$ das publicações são escritas por acadêmicos de diferentes áreas das ciências. É importante destacar a necessidade de integrar-se a academia com o mundo profissional para que as pesquisas possam ter resultados efetivos e práticos.
Há predomínio de pesquisas na área de Ciências Sociais Aplicadas, com pouco mais de 70\% das publicações. A única área temática que não apresentou estudos relacionados foi a de Ciências Humanas. Entretanto, ressalta-se a importância de desenvolvimento de estudos interdisciplinares que explorem como a interconexão da RSC com o RI poderia impactar na capacitação de contadores e administradores, envolvendo estas duas áreas citadas. Há espaço também para pesquisas associando a evidenciação e comunicação do RI, em aspectos relacionados ao capital social e de relacionamento das empresas, com as questões éticas, a organização e funcionamento das sociedades humanas e das leis que regem as relações sociais e as instituições ou o comportamento do ser humano e suas interações com o ambiente físico e social.

Assim, como o RI é um tema complexo e que relaciona gestão estratégica, informações financeiras, informações não financeiras, dados quantitativos, dados qualitativos, relatos sobre sustentabilidade, criação de valor e mecanismos de comunicação, fica evidente a importância do desenvolvimento de pesquisas de forma interdisciplinar, com a participação de pesquisadores de distintas áreas, a fim de chegar-se a um denominador comum em relação ao conteúdo informacional presente no tipo de documento. Portanto, é preciso integrar pesquisadores de diferentes áreas para que se possam realizar pesquisas de forma interdisciplinar.

\subsubsection{Informações metodológicas}

$\mathrm{O}$ paradigma de pesquisa mais utilizado em artigos sobre o RI associado ao meio ambiente, à sociedade, à sustentabilidade ou à RSC é o crítico, com $40 \%$ das pesquisas. Estas pesquisas buscam 
compreender a realidade de forma crítica com objetivo de contribuir para sua transformação e avanço. Assim, avaliaram criticamente os relatórios integrados para "ampliar" e "abrir" o diálogo e debater como os padrões contábeis e de relatórios podem ajudar ou obstruir os esforços para promover práticas comerciais sustentáveis (Brown \& Dillard, 2014); para identificar sua contribuição para sustentabilidade (Tweedie \& Martinov-Bennie, 2015); para verificar se podem ser usados como uma fonte relevante de informações para operacionalizar o modelo de RSC (Batista, 2018); e outros.

A pesquisa normativa também é bem desenvolvida: $27 \%$ das publicações, principalmente no que diz respeito à análise da divulgação, como a extensão atual da evidenciação de estratégias relacionadas a aspectos sociais, ambientais e econômicos de empresas listadas no setor de serviços financeiros da Bolsa de Valores de Joanesburgo (Van Zijl et al., 2017); à análise da política socioambiental (Woźniak \& Pactwa, 2019); à análise das divulgações de informações sociais e ambientais (Turturea, 2015) e outros.

Em terceiro lugar fica a pesquisa positiva, com $23 \%$ das publicações. Começaram a ser publicadas de forma mais expressiva a partir de 2015, com o intuito de identificar determinantes para o uso de relatórios integrados (Sierra-García et al., 2015; Vaz et al., 2016); examinar o impacto da adoção do RI na integração de questões ambientais, sociais e de governança no modelo de negócios (Maniora, 2017); determinar a relação entre informação social corporativa, preço das ações, volume de vendas e retorno sobre o patrimônio líquido entre as empresas de investimento socialmente responsável (Kobo \& Ngwakwe, 2017); comparar a qualidade das informações de sustentabilidade emitidas seguindo os três modelos de relatórios mais comuns: relatório anual (dirigido aos acionistas), relatório de sustentabilidade (dirigido às partes interessadas) e relatório integrado (dirigido aos acionistas), (Romero et al., 2018); e outros.

Os paradigmas normativos e interpretativistas são bem similares. Enquanto o primeiro investiga o nível de aderência da divulgação em dado normativo, o último investiga como determinada prática é aplicada. Entretanto, como informado na Tabela 1, o paradigma de pesquisa interpretativista é pouco utilizado. Apenas $10 \%$ das pesquisas utilizam esse paradigma, como Demartini et al. (2015), que exploraram o processo que levou à adoção de um RI, e Beck et al. (2017) e Camodeca \& Almici (2017), que investigaram a jornada de uma organização na elaboração de relatórios integrados.

A estratégia de pesquisa mais utiliza é a documental (44\%), utilizando a técnica de análise documental (35\%), referindo-se, na maioria das vezes, a pesquisas descritivas (40\%). Grande parte delas foi publicada em 2015, quando houve um pico de publicações de RI tratando de informações ambientais, sociais, de sustentabilidade e/ou RSC.

As pesquisas documentais que se utilizaram da análise descritiva empregam tanto documentos do IIRC, com o objetivo de identificar pontos importantes e desafios na implementação da estrutura proposta (Reuter \& Messner, 2015; Siew, 2015), como analisam suas implicações para a sustentabilidade (Adams, 2015; Flower, 2015; Thomson, 2015; Tweedie \& Martinov, 2015) e, até, os Relatos Integrados divulgados pelas empresas, seja para identificar as práticas de divulgação de informações não financeiras, como as sociais e ambientais, ou sua qualidade, baseados nas diretrizes do GRI (Buys \& Van Niekerk, 2014; Calu et al., 2015; Krasodomska, 2015; Woźniak \& Pactwa, 2019). 
Além das pesquisas descritivas, também se destacam as pesquisas exploratórias (37\%) e as pesquisas empírico-analíticas (23\%). Estas últimas adotam, predominantemente, uma estratégia experimental e técnicas de pesquisa múltiplas ou testes de hipóteses. Apenas um estudo adotou como estratégia a pesquisa ação, ou seja, teve o pesquisador participando e atuando no entorno estudado. Não foi identificada a adoção da observação ou da revisão sistemática da literatura como técnica de pesquisa para tratar as questões socioambientais em publicações de RI.

Apenas quatro publicações (8\%) utilizaram mais de uma perspectiva teórica para embasar o estudo; enquanto $27 \%$ das publicações não adotaram nenhuma base teórica para fundamentar a pesquisa. As perspectivas teóricas mais identificadas foram a dos stakeholders (17\%), a institucional (15\%) e a da legitimidade (10\%).

As pesquisas que usaram a teoria dos stakeholders buscaram compreender o papel das diversas partes interessadas na fase inicial de estabelecimento de padrões do IIRC, conseguindo identificar que estes foram escritos, principalmente, por grandes empresas multinacionais, em oposição a pequenas e médias empresas, e por preparadores, em oposição a usuários (Reuter, 2015); e como as empresas comunicaram sua criação de valor a seus diversos usuários por meio do RI (Dumitru et al., 2015). Soyka (2013) afirma que muitas ou a maioria das mudanças explicitamente exigidas ou implícitas pelo framework são necessárias ou desejadas por uma ampla gama de partes interessadas externas.

Entretanto, Flower (2015) e Batista (2018) ressaltam o foco que o RI dá ao investidor, ao determinar que o objetivo do Relato Integrado é demonstrar a criação de valor para o acionista, e não para a sociedade, não obrigando a empresa a relatar os danos infligidos a contextos externos, como ao meio ambiente e à sociedade, se não houver impactos subsequentes sobre a empresa.

As publicações baseadas na teoria institucional buscaram investigar os primeiros passos adotados por empresas que adotaram o RI (Stubbs \& Higgins, 2014; Camodeca \& Almici, 2017); compreender os fatores que impulsionam sua adoção, identificando como fatores importantes o nível de desenvolvimento econômico, ambiental e social e o grau de responsabilidade corporativa (Jensen \& Berg, 2012; Maniora, 2017); investigar a influência do RI nas práticas de relatórios de sustentabilidades, obtendo resultados que mostram um aumento constante na quantidade e qualidade das divulgações de sustentabilidade (Montecalvo et al., 2018) e outros.

Estudos baseados na perspectiva da teoria da legitimidade buscaram compreender como uma organização poderia ganhar legitimidade a partir de uma multiplicidade de visões do RI (Van Bommel, 2014), se a opção por fazer parte do projeto piloto do IIRC foi decorrente da necessidade de legitimidade (Lai et al., 2016) e outros.

Citam-se outras teorias menos identificadas no levantamento feito, mas que também contribuem para literatura sobre o tema, como a da sinalização e a da utilidade.

\subsubsection{Informações relacionadas ao processo contábil}

Boa parte das publicações analisadas não se relaciona com o processo contábil (42\%). Das que mantêm relação, quase metade está associada à divulgação (48\%). Neste sentido, discutem sobre: 
i) lacunas que podem ser preenchidas pelo RI nos relatórios não financeiros atuais (Lewis, 2011); ii) qualidade do RI (Buys \& Van Niekerk, 2014; Romero et al., 2018); iii) práticas de divulgação de Relato Integrado (Calu et al., 2015; Dumitru et al., 2015; Krasodomska, 2015; Turturea, 2015; Stacchezzini et al., 2016; Mervelskemper \& Streit, 2017; Rupley et al., 2017; Van Zijl et al., 2017; Albertini, 2019; Woźniak \& Pactwa, 2019); iv) reações iniciais da comunidade de investimento institucional da África do Sul aos primeiros conjuntos de relatórios integrados (Atkins \& Maroun, 2015); v) evolução dos Relatos Integrados (Mio \& Fasan, 2014; Adams et al., 2016).

Em contrapartida, há um número expressivamente reduzido de pesquisas que abordam o reconhecimento dos dados sociais, ambientais e de sustentabilidade por um RI (4\%), bem como sua classificação (2\%) e mensuração (4\%). A pesquisa de Demartini et al., (2015) foi classificada em duas categorias, pois propunha um modelo para a avaliação da mensuração e gestão dos ativos intangíveis e tratava do reconhecimento destes também. A outra pesquisa, que tratava de reconhecimento, tinha por objetivo resumir e analisar a estrutura do RI, orientando os leitores (Soyka, 2013).

As que trataram da mensuração propuseram KPIs para Relatos Integrados que decifrassem a sustentabilidade de uma empresa (Oshika \& Saka, 2017) e métricas de saúde e bem-estar para os Relatos Integrados (Pronk et al., 2018). A única pesquisa que abordava a classificação de informações propôs uma codificação para as categorias de risco divulgadas por empresas mineradoras (Moloi, 2015).

Observa-se que questões relacionadas à mensuração começaram a ser tratadas bem recentemente e ainda necessitam de um melhor desenvolvimento.

\subsubsection{Lacunas identificadas e questões para debate}

O estudo bibliográfico permitiu identificar ainda algumas lacunas que poderiam ser exploradas futuramente. Preenchendo estes gaps, haveria uma consolidação ou expansão da fronteira do conhecimento nesta área, conforme assinalado a seguir:

(1) A literatura que estuda o RI relacionando as questões de RSC tem recebido muito pouca atenção. Desta forma, pesquisas que investiguem quais informações sociais e ambientais devem ser identificadas, como devem ser reconhecidas, como podem ser mensuradas e divulgadas contribuirá para o desenvolvimento do tema e fortalecimento da sustentabilidade em RI.

(2) Não foram identificadas pesquisas que buscassem conhecer a percepção e o interesse dos investidores em relação às informações sociais e ambientais. Entretanto, é fundamental que sejam desenvolvidas pesquisas neste sentido, já que o RI tem como principal objetivo fornecer informações ao investidor dando subsídios para uma tomada de decisão mais sustentável.

(3) Observa-se, também, a ausência de pesquisas que investiguem como as informações sociais e ambientais em RI impactam o mercado de capitais. Esta análise é relevante, pois mostra a utilidade da informação e a importância em divulgá-la.

(4) Apenas um estudo com uso da estratégia de pesquisa ação foi identificado. Portanto, seria importante que mais pesquisas se utilizassem do desenvolvimento deste tipo de estratégia, dada a relevância da colaboração entre o pesquisador e o pesquisado na identificação de resultados efetivos. 
(5) Observou-se, também, que a rede de colaboração entre acadêmicos e profissionais é, ainda, muito reduzida. Seria de suma importância o desenvolvimento de pesquisas de forma colaborativa entre estes atores no intuito de preencher lacunas existentes entre a teoria e a prática.

\section{Considerações finais}

Esta pesquisa analisou como a RSC é relacionada em estudos que contemplam o tema RI. Para isto, realizou-se uma análise bibliométrica seguida de uma análise exploratória, no intuito de analisar a evolução da produção científica sobre RI e sua relação com questões ambientais, sociais e de sustentabilidade, no período de 2010 a junho 2019.

A análise dos documentos levantados mostrou a pouca atenção que é dada à questão social e ambiental nas pesquisas acadêmica sobre o RI. Menos de 15\% das publicações sobre RI, na base Scopus, tratam de questões sociais e ambientais. Desta forma, faz-se necessário que sejam desenvolvidas pesquisas neste sentido, principalmente no que tange ao reconhecimento, à classificação, à mensuração e à divulgação das informações sociais e ambientais.

A análise bibliométrica permitiu identificar os autores mais relevantes (Jensen \& Berg, 2012; Brown \& Dillard, 2014; Stubbs \& Higgins, 2014; Adams, 2015; Flower, 2015), tornando-se imprescindível a leitura de suas publicações ao iniciar-se uma pesquisa que integre o RI e a RSC.

O periódico mais dedicado ao tema é o $A c$ counting Auditing and Accountability Journal.

Observou-se a necessidade do desenvolvimento de redes de pesquisa fortes e atuantes na investigação de questões sociais, ambientais e de sustentabilidade em investigações sobre RI. Apenas uma rede foi identificada com duas publicações.

Em relação ao processo metodológico, destaca-se o pequeno interesse no estudo de organizações específicas. O desenvolvimento de estudos de caso em organizações específicas poderia contribuir para o melhor entendimento sobre a prática do processo de adoção e a prática de divulgação do RI pelas empresas. Nesse sentido, a adoção de uma abordagem interpretativista e da estratégia da pesquisa ação poderia favorecer o desenvolvimento de investigações com resultados efetivos na resolução de problemas práticos, que poderiam servir de benchmarking para outras organizações. A compreensão do processo de adoção e divulgação do RI, principalmente em relação à evidenciação de informações sociais e ambientais, pode ser um direcionador para novos adotantes.

Além disso, verifica-se a necessidade do desenvolvimento destas pesquisas no Brasil, no intuito de analisar-se como está sendo realizado o processo de adoção do RI pelas empresas brasileiras e como elas estão divulgando as informações sociais, ambientais e de sustentabilidade em seus Relatos Integrados.

Os autores acreditam que o artigo em tela traz contribuições relevantes para a área de pesquisa acadêmica, situando o atual estágio de investigação científica sobre o RI relacionado a questões sociais, ambientais e de sustentabilidade. Ademais, aponta como a ciência poderia avançar nesta área e contribuir com a solidificação de informações de sustentabilidade neste tipo de relatório. 


\section{Referências}

Adams, C. A. The international integrated reporting council: A call to action. Critical Perspectives on Accounting, 27, 23-28, 2015. doi: 10.1016/j.cpa.2014.07.001

Adams, C. A.; Potter, B.; Singh, P.; York, J. Exploring the implications of integrated reporting for social investment (disclosures). British Accounting Review, 48 (3), 283-296, 2016. doi: 10.1016/j.bar.2016.05.002

Adams, S.; Simnett, R. Integrated Reporting: An Opportunity for Australia's Not-for-Profit Sector. Australian Accounting Review, 21(3), 292-301, 2011. doi: 10.1111/j. 1835-2561.2011.00143.x

Ahmed Haji, A.; Anifowose, M. Initial trends in corporate disclosures following the introduction of integrated reporting practice in South Africa. Journal of Intellectual Capital, 18(2), 373-399, 2017. doi: 10.1108/JIC-01-2016-0020

Albertini, E. Integrated reporting: an exploratory study of French companies. Journal of Management and Governance, 23(2), 513-535, 2019. doi: 10.1007/s10997-018-9428-6

Alexander, D.; Blum, V. Ecological economics: A Luhmannian analysis of integrated reporting, Ecological Economics, 129(C), 241-251, 2016. doi: 10.1016/j.ecolecon.2016.06.020

Atkins, J.; Maroun, W. Integrated reporting in South Africa in 2012: Perspectives from South African institutional investors. Meditari Accountancy Research, 23(2), 197-221, 2015. doi: 10.1108/MEDAR-07-2014-0047

Barth, M. E; Cahan, S. F.; VChen, L.; Venter, E. R. The Economic Consequences Associated with Integrated Report Quality: Capital Market and Real Effects. Accounting, Organizations and Society, 62, 43-64, 2017.

Baboukardos, D.; Rimmel, G. Value Relevance of Accounting Information Under an Integrated Reporting Approach: A Research Note. Journal of Accounting and Public Policy, 35(4), 437-452, 2016. Disponível em: https://ssrn.com/ abstract $=2740703$.

Batista, N. Integrated reporting stimulates strategic communication of corporate social responsibility? A marketing perspective analysis based on Maignan, Ferrell and Ferrell's stakeholder model of corporate social responsibility in marketing. Media e Jornalismo, 18(33), 43-59, 2018. doi: 10.14195/2183-5462_33_3

Beck, C.; Dumay, J.; Frost, G. In Pursuit of a 'Single Source of Truth': from Threatened Legitimacy to Integrated Reporting. Journal of Business Ethics, 141(1), 191-205, 2017. doi: 10.1007/s10551-014-2423-1

Bonjardim, E. C.; Pereira, R. D. S.; Guardabassio, E. V. Análise bibliométrica das publicações em quatro eventos científicos sobre gestão de resíduos sólidos urbanos a partir da Política Nacional de resíduos Sólidos - Lei n ${ }^{\circ}$ 12.305/2010. Desenvolvimento e Meio Ambiente, 46, 313-333, 2018. doi: 10.5380/dma.v46i0.53722

Brown, J.; Dillard, J. Integrated reporting: On the need for broadening out and opening up. Accounting, Auditing \& Accountability Journal, 27(7), 1120-1156, 2014. doi: 10.1108/AAAJ-04-2013-1313

Buys, P.; Van Niekerk, E. The South African financial services industry's integrated reporting compliance with the global reporting initiative framework. Banks and Bank Systems, 9(4), 107-124, 2014. Disponível em: https://businessperspectives.org/media/zoo/applications/publishing/ templates/article/assets/js/pdfjs/web/6103

Calu, A.; Negrei, C.; Calu, D. A.; Avram, V. Reporting of Non-Financial Performance Indicators - a Useful Tool for a Sustainable Marketing Strategy. Amfiteatru Economic, 17(40), 977-993, 2015. Disponível em: https://ssrn.com/ abstract $=2850857$.

Camodeca, R.; Almici, A. From the corporate social responsibility reporting to the integrated reporting: The case of Sabaf S.p.a. Problems and Perspectives in Management, 15(1), 150-157, 2017. doi: 10.21511/ppm.15(1-1).2017.01

de Villiers, C.; Rinaldi, L.; Unerman, J. Integrated Reporting: Insights, gaps and an agenda for future research. Accounting, Auditing \& Accountability Journal, 27(7), 1042-1067, 2014. doi: 10.1108/AAAJ-06-2014-1736

de Villiers, C.; Rinaldi, L.; Unerman, J. Special issue on Case study insights from the implementation of Integrated Reporting. 2015. Disponível em: http://www.emeraldgrouppublishing.com/authors/writing/calls.htm?id=6194. 
de Villiers, C.; Venter, E. R.; Hsiao, P. C. K. Integrated reporting: background, measurement issues, approaches and an agenda for future research. Accounting \& Finance, 57 (4), 937-959, 2017. doi:10.1111/acfi.12246

Demartini, P.; Paoloni, M.; Paoloni, P. Sustainability and Intangibles: Evidence of Integrated Thinking. Journal of International Business and Economics, 15(2), 107-122, 2015. doi: 10.18374/JIBE-15-2.9

Dumay J.; Bernardi C.; Guthrie J.; Demartini P. Integrated reporting: A structured literature review, Accounting Forum, 40(3), 166-185, 2016. doi: 10.1016/j.accfor.2016.06.001

Dumitru, M.; Gușe, R. G.; Feleagă, L.; Mangiuc, D. M.; Feldioreanu, A. I. Marketing Communications of Value Creation in Sustainable Organizations. The Practice of Integrated Reports. Amfiteatru Economic Journal, 17, 955-976, 2015. Disponível em: https://www.econstor.eu/ handle/10419/168959.

Eccles, R. G.; Serafeim, G. Corporate and Integrated Reporting: A Functional Perspective. In: Lawyer, E.; Mohrman, S.; O'Tolle, J. (Eds.). Corporate Stewardship: Achieving Sustainable Effectiveness. Austin, TX, EUA: Greenleaf, 2015. p. 156-172. Disponível em: https://ssrn.com/abstract $=2388716$. doi: $10.2139 /$ ssrn. 2388716

European Commission. Proposal for a directive of the European Parliament and of the Council: amending Council Directives 78/660/EEC and 83/349/EEC as regards disclosure of nonfinancial and diversity information by certain large companies and groups. Strasbourg: European Union, 2013. Disponível em: <https://eur-lex.europa.eu/LexUriServ/LexUriServ.do?uri=COM:2013:0207:FIN:EN:PDF>. Acesso em: junho 2019.

Elsevier. Sobre a solução SCOPUS. Disponível em: https:// www.elsevier.com/pt-br/solutions/scopus. Acesso em: abr. 2019.

Flower, J. The International Integrated Reporting Council: A story of failure. Critical Perspectives on Accounting, 27, 1-17, 2015. doi: 10.1016/j.cpa.2014.07.002

Fonseca, F. Framework do Relato Integrado. São Paulo: NECMA/USP, 2015. Disponível em: http://www.erudito. fea.usp.br/portalFEA/Repositorio/3581/Documentos/Palestra $\% 20$ Fernando\%20Fonseca $\% 2001$ set 156 .pdf. Acesso em: mai. 2019.

García-Sánchez, I. M.; Noguera-Gámez, L. Integrated information and the cost of capital. International Business Review, 26(5), 959-975, 2017. doi: 10.1016/j.ibusrev.2017.03.004

Giorgino, M. C.; Supino, E.; Barnabè, F. Corporate Disclosure, Materiality, and Integrated Report: An Event Study Analysis. Sustainability, 9(12), 1-15, 2017. doi:10.3390/ su9122182

IIRC - International Integrated Reporting Council. The international $\langle I R>$ framework. London: The International Integrated Reporting Council, 2013a. Disponível em: <https://integratedreporting.org/wp-content/uploads/2013/12/13-12-08-THE-INTERNATIONAL-IR-FRAMEWORK-2-1.pdf $>$. Acesso em: jan. 2019.

IIRC - International Integrated Reporting Council. Capitals - Background Paper for IR. London: The International Integrated Reporting Council, 2013b. Disponível em: https://integratedreporting.org/wp-content/uploads/2013/03/ IR-Background-Paper-Capitals.pdf. Acesso em: jan. 2019.

Jensen, J. C.; Berg, N. Determinants of Traditional Sustainability Reporting Versus Integrated Reporting. An Institutionalist Approach. Business Strategy and the Environment, 21(5), 299-316, 2012. doi: 10.1002/bse.740

Kobo, K. L.; Ngwakwe, C. C. Relating corporate social investment with financial performance. Investment Management and Financial Innovations, 14(2), 367-375, 2017. doi: 10.21511/imfi.14(2-2).2017.08

KPMG. The KPMG Survey of Corporate Responsibility Reporting 2017. KPMG Swiss: International Cooperative (“KPMG International"), 2017. Disponível em: $<$ https:// home.kpmg/content/dam/kpmg/campaigns/csr/pdf/CSR Reporting_2017.pdf>. Acesso em: fev. 2019.

Kuzina, R. W. Integrated Reporting as a Strategic Mechanism. Actual Problems of Economics, 8(158), 385-392, 2014. doi: 10.1108/MEDAR-11-2016-0099

Krasodomska, J. CSR disclosures in the banking industry. Empirical evidence from Poland, Social Responsibility Journal, 11(3), 406-423, 2015. doi: 10.1108/SRJ-02-2013-0019 Lai, A.; Melloni, G.; Stacchezzini, R. Corporate Sustainable 
Development: Is "Integrated Reporting" a Legitimation Strategy? Business Strategy and the Environment, 25(3), 165-177, 2016. doi:10.1002/bse.1863

Lee, K. W.; Yeo, G. H. H. The association between integrated reporting and firm valuation. Review of Quantitative Finance and Accounting, 47(4), 1221-1250, 2016.

Lewis, S. Lessons on corporate "Sustainability" disclosure from deepwater Horizon. New Solutions, 21(2), 197-214, 2011. doi: 10.2190/NS.21.2.d

Maniora, J. Is Integrated Reporting Really the Superior Mechanism for the Integration of Ethics into the Core Business Model? An Empirical Analysis. Journal of Business Ethics, 140(4), 755-786, 2017. doi: 10.1007/s10551-015-2874-z

Massaro, M.; Dumay, J.; Guthrie, J. On the shoulders of giants: undertaking a structured literature review in accounting. Accounting, Auditing \& Accountability Journal, 29(5), 767-801, 2016. doi: 10.1108/AAAJ-01-2015-1939

Mervelskemper, L.; Streit, D. Enhancing Market Valuation of ESG Performance: Is Integrated Reporting Keeping its Promise? Business Strategy and the Environment, 26(4), 536-549, 2017. doi: 10.1002/bse.1935

Milne, M. J.; Gray, R. Wither Ecology? The Triple Bottom Line, the Global Reporting Initiative, and the Institutionalization of Corporate Sustainability Reporting. Journal of Business Ethics, 118(1), 13-29, 2013. doi: 10.1007/ s10551-012-1543-8

Mio, C.; Fasan, M. Beyond Financial Reporting: A Journey from Sustainability towards Integrated Re-porting. Journal of Environmental Accounting and Management. 2(3), 189203, 2014. doi: 10.5890/JEAM.2014.09.001

Mohamed A. O.; Ahmed M. El-G. Theoretical perspectives on corporate disclosure: a critical evaluation and literature survey. Asian Review of Accounting, 22(3), 257-286, 2014. doi: 10.1108/ARA-01-2014-0013

Moloi, T. A critical examination of risks disclosed by South African mining companies' pre and posts Marikana event. Problems and Perspectives in Management, 13(4), 168-176, 2015.

Montecalvo, M.; Farneti, F.; de Villers, C. The potential of integrated reporting to enhance sustainability reporting in the public sector. Public Money \& Management, 38(5), 365-374, 2018. doi: 10.1080/09540962.2018.1477675

Morais, C. M.; Zevericoski, G. A.; Ferrarezi, J. S.; Gehlen, K. R. H.; Reis, L. G. Produção Acadêmica Brasileira no Contexto dos Relatórios de Sustentabilidade: Uma Análise Bibliométrica. Revista de Gestão, Finanças e Contabilidade, 7(2), 197-217, 2017. doi: 10.18028/2238-5320/ rgfc. v7n2p197-217

Ocean Tomo. Intangible Asset Market Value Study, 2019. Disponível em: $<$ https://www.oceantomo.com/intangible-asset-market-value-study/>. Acesso em: fev. 2019.

Oshika, T.; Saka, C. Sustainability KPIs for integrated reporting. Social Responsibility Journal, 13(3), 625-642, 2017. doi: 10.1108/SRJ-07-2016-0122

Pronk, N. P.; Malan, D.; Christie, G.; Hajat, C.; Yach, D. Health and well-being metrics in business: The value of integrated reporting. Journal of Occupational and Environmental Medicine, 60(1), 19-22, 2018. doi: 10.1097/ JOM.0000000000001167

Rambe, P.; Mangara, T. B. Influence of integrated reporting ratings, CEO age, and years of experience on the share price of top 106 JSE listed companies. Problems and Perspectives in Management, 14(3), 216-231, 2016. doi: 10.21511/ ppm.14(3-1).2016.08

Reis, L. G.; Tarifa, M. Contabilidade e sustentabilidade: uma análise dos artigos publicados em periódicos Qualis no período de 2007 a 2011. Revista de contabilidade da UFBA, 8(3), 21-37, 2014. Disponível em: https://portalseer.ufba.br/ index.php/rcontabilidade/article/view/8357/9101

Reuter, M.; Messner, M. Lobbying on the integrated reporting framework. Accounting, Auditing \& Accountability Journal, 28(3), 365-402, 2015. doi: 10.1108/AAAJ-032013-1289

Rinaldi, L.; Unerman, J.; de Villiers, C. Evaluating the integrated reporting journey: insights, gaps and agendas for future research. Accounting, Auditing \& Accountability Journal, 31(5), 1294-1318, 2018. doi: 10.1108/AAAJ-042018-3446

Romero, S.; Ruiz, S.; Fernandez-Feijoo, B. Sustainability reporting and stakeholder engagement in Spain: Different 
instruments, different quality. Business Strategy and the Environment, 28(1), 221-232, 2018. doi: 10.1002/bse.2251

Rupley, K. H.; Brown, D.; Marshall, S. Evolution of corporate reporting: From stand-alone corporate social responsibility reporting to integrated reporting. Research in Accounting Regulation, 29(2), 172-176, 2017.

Sierra-García, L.; Zorio-Grima, A.; García-Benau, M. A. Stakeholder Engagement, Corporate Social Responsibility and Integrated Reporting: An Exploratory Study. Corporate Social Responsibility and Environmental Management, 22(5), 286-304, 2015. doi: 10.1002/csr.1345

Siew, R. Y. J. R. Briefing: Integrates Reporting - challenges in the construction industry. Proceedings of the Institution of Civil Engineers - Engineering Sustainability, 168(1), 3-6, 2015. doi: 10.1680/ensu.14.00039

Slewinski, E.; Camacho, R. R.; Sanches, S. L. R. Análise Bibliométrica e Paradigmática da Produção Científica sobre Relato Integrado nos Periódicos Internacionais de Contabilidade. In: Anais do XV Congresso USP de Controladoria e Contabilidade. São Paulo, 29 a 31 de julho, 2015.

Soyka, P. A. The International Integrated Reporting Toward Better Reporting Framework: Council (IIRC) Integrated Sustainability Reporting and (Way) Beyond. Environmental Quality Management, 49(4), 16-18, 2013. doi: 10.1002/ tqem.21357

SSE - Sustainable Stock Exchanges. 2018 Report on Progress. A paper prepared for the Sustainable Stock Exchanges 2018 Global Dialogue. New York: United Nations Sustainable Stock Exchanges (SSE), 2018. Disponível em: $<$ http://www.sseinitiative.org/wp-content/uploads/2018/10/ SSE_On_Progress_Report_FINAL.pdf $>$. Acesso em: mai. 2019.

Stacchezzini, R.; Melloni, G.; Lai, A. Sustainability management and reporting: the role of integrated reporting for communicating corporate sustainability management. Journal of Cleaner Production, 136(10), 102-110, 2016. doi: 10.1016/j.jclepro.2016.01.109

Stent, W.; Dowler, T. Early assessments of the gap between integrated reporting and current corporate reporting. Meditari Accountancy Research, 23(1), 92-117, 2015. doi: 10.1108/MEDAR-02-2014-0026
Stubbs, W.; Higgins, C. Integrated reporting and internal mechanisms of change. Accounting, Auditing and Accountability Journal, 27(7), 1068-1089, 2014. doi: 10.1108/ AAAJ-03-2013-1279

Suchman, M. C. Managing legitimacy: Strategic and institutional approaches. Academy of Management Review, 20(3), 571-610, 1995. doi: 10.2307/258788

Tachizawa, T. Gestão Ambiental e Responsabilidade Social Corporativa: Estratégias de Negócios Focadas na Realidade Brasileira. São Paulo: Atlas, 8 ed., 2014.

Tinoco, J. E. P. Balanço Social: uma abordagem da transparência e da responsabilidade pública das organizações. São Paulo: Atlas, 2001.

Thomson, I. "But does sustainability need capitalism or an integrated report" a commentary on "The International Integrated Reporting Council: A story of failure" by Flower, J. Critical Perspectives on Accounting, 27, 18-22, 2015. doi: 10.1016/j.cpa.2014.07.003

Turturea, M. Social and Environmental Reporting as a Part of the Integrated Reporting. Acta Universitatis Agriculturae et Silviculturae Mendelianae Brunensis, 63(6), 2161-2170, 2015. doi: 10.11118/actaun201563062161

Tweedie, D.; Martinov-Bennie, N. Entitlements and Time: Integrated Reporting's Double-edged Agenda. Social and Environmental Accountability Journal, 35(1), 49-61, 2015. doi: 10.1080/0969160X.2015.1007466

United Nations. Best Practice Guidance for Policymakers and Stock Exchanges on Sustainability Reporting Initiatives. New York; Geneva: United Nations Conference on Trade and Development - UNCTAD, 2014. Disponível em: https:// unctad.org/en/PublicationsLibrary/diaeed2013d6_en.pdf. Acesso em: março 2019.

Van Bommel, K. Towards a legitimate compromise? Accounting, Auditing \& Accountability Journal, 27(7), 11571189, 2014. doi: 10.1108/AAAJ-04-2013-1309

Van Eck, N.J; Waltman, L. Software survey: VOSviewer, a computer program for bibliometric mapping. Scientometrics, 84(2), 523-538, 2010. doi: 10.1007/s11192-009-0146-3

Van Eck, N. J.; Waltman, L. Visualizing bibliometric networks. In: Ding, Y.; Rousseau, R.; Wolfram, D. (Eds.). 
Measuring scholarly impact: Methods and practice Nova York; London: Springer International Publishing, 2014. p. 285-320. doi: 10.1007/978-3-319-10377-8_13

Van Zijl, W.; Wöstmann, C.; Maroun, W. Strategy disclosures by listed financial services companies: Signalling theory, legitimacy theory and South African integrated reporting practices. South African Journal of Business Management, 48(3), 73-85, 2017. doi: 10.4102/sajbm.v48i3.37

Vaz, N.; Fernandez-Feijoo, B.; Ruiz, S. Integrated reporting: an international overview. Business Ethics, 25(4), 577-591, 2016. doi: $10.1111 /$ beer. 12125

World Economic Forum. The Global Risks Report 2019, 14 ${ }^{\text {th }}$ Edition, Geneva: World Economic Forum, 2019. Disponível em: $<$ http://www3.weforum.org/docs/WEF_Global_Risks_ Report_2019.pdf>. Acesso em: fev. 2019.

Woźniak, J.; Pactwa. K. Analysis of the socio-environmental policy of selected mining companies on the basis of non-financial reporting. Gospodarka Surowcami Mineralnymi - Mineral Resources Management, 35(1), 177-194, 2019. doi: $10.24425 / \mathrm{gsm} .2019 .128206$

Zhou, S.; Simnett, R.; Green, W. Does Integrated Reporting Matter to the Capital Market? Abacus, 53(1), 94-132, 2017. doi: 10.1111/abac.12104 